\title{
Development and Evaluation of a Flexible Interface for a Wheelchair Mounted Robotic Arm
}

\author{
Katherine Tsui and Holly Yanco \\ University of Massachusetts Lowell \\ Department of Computer Science \\ One University Avenue \\ Lowell, MA 01854 \\ ktsui@cs.uml.edu \\ holly@cs.uml.edu
}

\author{
David Kontak and Linda Beliveau \\ Crotched Mountain Rehabilitation Center \\ Assistive Technology Unit \\ One Verney Drive \\ Greenfield, NH 03047 \\ david.kontak@crotchedmountain.org \\ linda.beliveau@crotchedmountain.org
}

\begin{abstract}
Accessibility is a challenge for people with disabilities. Differences in cognitive ability, sensory impairments, motor dexterity, behavioral skills, and social skills must be taken into account when designing interfaces for assistive devices. Flexible interfaces tuned for individuals, instead of custombuilt solutions, may benefit a larger number of people. The development and evaluation of a flexible interface for controlling a wheelchair mounted robotic arm is described in this paper. There are four versions of the interface based on input device (touch screen or joystick) and a moving or stationary shoulder camera. We describe results from an eight week experiment conducted with representative end users who range in physical and cognitive ability.
\end{abstract}

\section{Categories and Subject Descriptors}

H.5.2 [Information Systems]: Information Interfaces and Presentation-User Interfaces

\section{General Terms}

Design, Human Factors, Measurement, Performance

\section{Keywords}

Human-robot interaction, assistive technology, robotic arm

\section{INTRODUCTION}

Accessibility, the ability of a person to understand and manipulate a device, is a significant challenge for people with disabilities. People with disabilities may have a wide range of strengths and challenges. These differences may be differences in cognitive ability, sensory impairments, motor dexterity, behavioral skills, and social skills [19]. Cognitive differences may be seen when a person is performing tasks that require problem solving or memory skills. Sensory skill

Permission to make digital or hard copies of all or part of this work for personal or classroom use is granted without fee provided that copies are not made or distributed for profit or commercial advantage and that copies bear this notice and the full citation on the first page. To copy otherwise, to republish, to post on servers or to redistribute to lists, requires prior specific permission and/or a fee.

HRI'08, March 12-15, 2008, Amsterdam, The Netherlands.

Copyright 2008 ACM 978-1-60558-017-3/08/03 ...\$5.00. issues are evident when a person has vision or hearing loss, tactile challenges, or difficulty concentrating in distracting environments. Motor demands can be a barrier when a task involves isolating individual fingers, aiming at small targets, or other precise or graded movements. Many tasks require frustration tolerance, impulse control, turn taking, and other social skills.

Devices designed to assist this population must take into account these differences. There are always alternative ways to accomplish a given task. Generally, an area of strength can be utilized to overcome a weaker area. Compensatory techniques can be used in all areas of accessibility. For example, procedural modifications such as increased prompting or feedback may assist with cognitive challenges. Vision impairments may be supplemented using auditory feedback, increased size/contrast, or tactile prompts. Alternative physical access may use voice commands or other adapted interfaces, such as special mounting to compensate for reduced range of motion, the use of foot or head controls, or single switch systems.

Each person is unique, and often has his/her own customized solution. Generalizations over populations cannot be made for human-robot interaction (HRI) in assistive technology (AT). We must also take into account the differences in cognitive ability, sensory impairments, motor dexterity, and behavior and social skills when designing HRI for people with disabilities. We propose the following HRI-AT design guidelines, inspired by the research fields of usability, human computer interaction, and adaptive user interfaces $[14,15$, $3,11]$ :

1. Interfaces should be easy to use without being trivial.

2. Interfaces should have minimal length processes. A person with a cognitive impairment may not have the ability to carry out multi-step processes.

3. Interfaces should adjust prompting levels. A person may require some form of prompting to perform a process.

4. Interfaces should leverage a person's sensory skills to augment their feedback.

5. Interfaces should accommodate multiple access devices. Slight variations in the interface may be required to support a variety of similarly purposed access devices. 
The system described in this paper provided a vision controlled flexible interface for operating a wheelchair robotic arm. The interface was a design collaboration between roboticists and occupational therapists. It adheres to the proposed guidelines with the exception of the prompting adjustment.

There are four versions of the interface based on input device (touch screen or joystick) and a moving or stationary shoulder camera, which approximates the user-eye view. In the first two interfaces, the shoulder camera remains fixed, as if a person were already focused on a particular area. The user clicks on an object to indicate selection. In the other two interfaces, the shoulder camera is able to be panned and tilted to adjust the view. This is similar to a person seeing something out of the corner of their eye, and then turning to focus on it. The user centers the camera on an object to indicate selection.

The robot arm then unfolds and moves towards the object. The robot arm centers on the object, keeping the object in its view during the approach. When complete, the robot arm's gripper has the object in view, positioned twelve inches or less from it. ${ }^{1}$

\section{BACKGROUND AND RELATED WORK}

\subsection{Developing Interfaces for Disabled People}

Adaptive user interfaces and user modeling are two techniques to increase interaction quality and user performance. Adaptive interfaces respond dynamically during use based on the user's previous interactions. For example, the Enhanced Network Accessibility for the Blind and Visually Impaired project proposes an adaptive architecture to improve internet accessibility; based on a user profile, assistive devices, and web content, the content will present itself differently in a visual, tactile, and auditory manner [16].

User modeling is used in human computer interaction; for example, GOMS (goals, operators, methods, and selection rules) [3]. However, user modeling of people with disabilities is considerably more difficult given the uniqueness of each patient. There have been a few approaches including word completion and prediction and user profiles describing hand force, hand workspace, disability type, assistive aid type, and preferences $[1,7]$.

Human-robot interaction for assistive technology (HRIAT) lies at the cross-section of many research fields including robotics (e.g. [12], [13]), human computer interaction (e.g. [3]), human factors (e.g. [8]), and universal usability (e.g. [20]). Our interface was created for a target population of cognitively impaired wheelchair patients to allow greater independence in their daily lives.

\subsection{Manus ARM Interfaces}

The Manus ARM is a wheelchair mounted robot arm which functions in unstructured environments. However, in its off-the-shelf state, it is awkwardly controlled through menus using a keypad, a joystick, or a single switch. This control is not intuitive or natural because it requires a high level of cognitive awareness. Also, the input devices may not correlate well to the user's physical capabilities.

Several research institutions are investigating more intuitive interfaces for the Manus ARM. At the New Jersey Insti-

\footnotetext{
${ }^{1}$ This research has focused on the interface development and gross motion. Fine motor control to pick up the object is still under development.
}

tute of Technology, Athanasiou et al. proposed three alternative interfaces for the Manus ARM: an infrared sensory box, a stylus with joints mimicking the robot arm, and a computer mouse [2]. At TNO Science \& Industry and the Delft University of Technology, the Manus ARM has been augmented with cameras, force torque sensors, and infrared distance sensors. It is operated by a wheelchair joystick and a switch in "pilot mode" shared autonomy between the robot arm and the user [4] [17].

At INRIA (Institut National de Recherche en Informatique et en Automatique), Dune et al. explores a "one click" computer vision approach. The robot arm is equipped with two cameras. The "eye-in-hand" camera offers a fixed overview of the workspace and the "eye-to-hand" camera offers detailed views of the scene. The user clicks on the desired object [9]. Then the robot arm move towards the object using a visual servoing scheme along the corresponding epipolar line [5].

We are also investigating a visual-based interface using a human-in-the-loop approach. In the summer of 2006, a prototype interface for single switch scanning used a video feed overlaid with a red rectangle which would cycle over quadrants. When the highlighted quadrant contained the desired object, the user would click a switch. The process would repeat once more, and the end result would be a onesixteenth view of the original view. The robot arm moved to the desired $X Y$ position using color tracking [18].

In an evaluation of our prototype interface by an occupational therapist, it was mentioned that the single switch scanning access method is difficult for cognitively impaired users. Some users may find difficulty in the timing aspect of when to press the switch. Other users may have difficulty with the multi-step process and remembering the abstraction of the red rectangle for selection. Many users are already able to drive a powered wheelchair with a joystick, access a computer with a joystick or touch screen, or both. To adhere to the second proposed guideline, the latest revision of our interface, described in this paper, leverages the well established access methods as well as intuitions on how humans view a scene and focus on particular items.

\section{SYSTEM OVERVIEW}

The trajectory of a human arm picking up an object is two separate events: the gross reaching motion to the intended location, followed by the fine adjustment of the hand [21]. The focus of this paper is a visual user interface developed for the gross motion of the robot arm. Figure 1 depicts the data flow of our system.

The robot in our system is an Exact Dynamics Manus Assistive Robotic Manipulator (ARM) [6]. It has a twofingered gripper end-effector and is a $6+2$ degree of freedom wheelchair mounted robot arm. The Manus ARM has been augmented with a pan-tilt-zoom camera on the shoulder to provide the perspective of the wheelchair occupant and a small camera within the gripper to show the up close view. The gripper camera has been tuned to similar color, hue, contrast, and brightness as the shoulder camera.

We have created a multi-modal interface that can be tuned for specific access methods. The focus of the interface is largely the shoulder camera view which is assumed to be similar to the wheelchair occupant's view. This design is consistent with the prototype interface. The system draws inspiration from people's innate abilities to see and touch, 


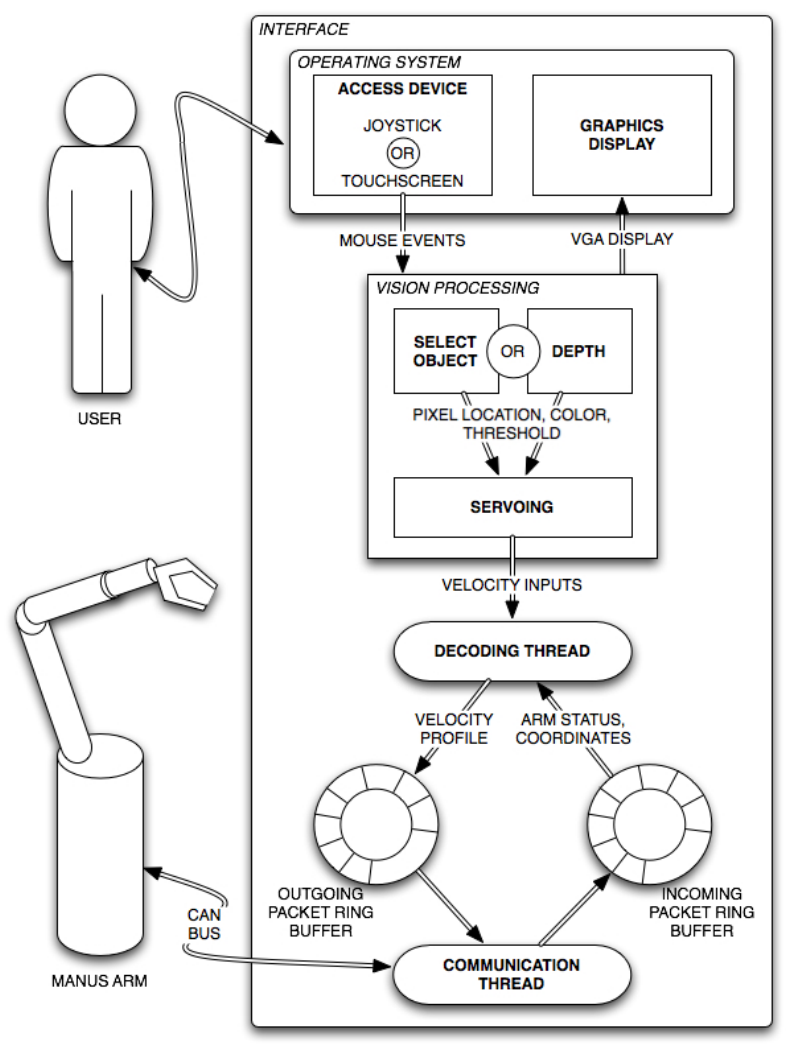

Figure 1: Data flow of the human-in-the-loop visual control system for the Manus ARM. The user gives input via a touch screen or joystick mouse (top). The input is used in vision processing (center) to position the robot arm (bottom).

the shoulder camera is able to be stationary or moving. If the shoulder camera is stationary, then the interface is simply the video feed for both joystick and touch screen access methods (see Figure 2 (left)).

When the shoulder camera is moved, thin black cross hairs outlined in white are overlaid on the video. A bolder, black plus overlaid on the cross hairs emphasizes the center of the screen. If the access method is a joystick, Figure 2 (center) is the resulting interface and the cursor is hidden. If the access method is a touch screen, the resulting interface is Figure 2 (right), which had blue semi-transparent buttons added at the top, bottom, left, and right with corresponding indicator arrows. Also, as the shoulder camera is panned and tilted, unreachable regions for the robot arm are not displayed, instead shown as white areas.

The interface also has tunable parameters for the user. Cursor size can be set to a small (32x32 pixels), medium (48x48 pixels), or large (64x64 pixels) cursor enhanced with a white outline. Cursor speed can be set for interfaces where the joystick is the designated access method. Another tunable parameter is a dwell period for users who are not easily able to move between a joystick and a button.

To control the robot arm, the user selects an object in the scene from the interface. The interface then determines if it is viable or not. The region below the tip of the cursor or "plus sign" is analyzed with respect to color in the HSV color space. If a color is able to be discerned, a bold, red rectangle appears around or on it and a "ding" plays. The $2 \mathrm{D}$ point location and HSV color and threshold are recorded. Otherwise, the user is prompted to "Please try again!"

Given a successful selection, the $2 \mathrm{D}$ point is converted from pixel coordinates to robot arm coordinates. The Manus ARM unfolds from its closed position and moves to the given coordinates in $x y$. When the end-effector arrives at the $x y$ position, the robot arm "drops" for $z$. The robot arm uses the HSV color and threshold values to center on the largest blob in its gripper camera view. It moves towards the object until at least $30 \%$ is in view. The robot then snaps a picture showing the up close view of the object, which is displayed to the user, and folds back into its closed position.

\section{HYPOTHESES}

An experiment was designed to investigate several of our hypotheses about this flexible interface. These intuitions address the appropriateness of vision-based input and the complexity of the menu hierarchy.

Hypothesis 1: The versions of the flexible interface are easy to used without being trivial.

The flexible interface was designed and created with our HRI-AT guidelines in mind. It accommodates the multiple access devices (guideline 5), uses audio feed back in addition to visual (guideline 4), and has at most a two-step process for object selection (guideline 2). ${ }^{2}$ However, the first HRI-AT guideline, that the interface not be frustrating and discouraging, is subjective.

Hypothesis 2: It should be easier to select an object from a fixed camera view than a moving camera view.

Assuming that the user has finger isolation to use a touch screen or good control of a joystick, the fixed camera interfaces should have faster object selection times. For the touch screen, the process is a single step. The user puts their finger on top of the object. The joystick emulates a mouse. Normal use of the joystick as computer input would be to move the mouse cursor with the joystick and press the yellow button (or an external switch connected to the yellow button input) to click. This selection can be viewed discretely as a two step process, but more so as a complete skill. Both access methods are considered direct selection methods in assistive technology.

For the moving camera view, there is a layer of abstraction that does not exist with the fixed camera view. The user must have the ability to reason how to aim the camera towards the object, which may or may not be within the current camera view. Physically, the process is always two steps: center the camera on the object and press the external button. To move the camera's view, the user must press a button on the touch screen or use a joystick to the corresponding direction (up, down, left, and right). However, the user must have the ability to reason how to aim the camera towards the object.

Hypothesis 3: A correlation exists between physical and cognitive abilities and interface performance.

One goal of this research is to understand which interface works well for a particular type of patient. A participant profile includes information on computer access method, visual ability, cognitive ability, and behavioral skills, as seen

\footnotetext{
${ }^{2}$ At this point, the third guideline of adjustable prompting is not incorporated. The experimenter prompted the user.
} 


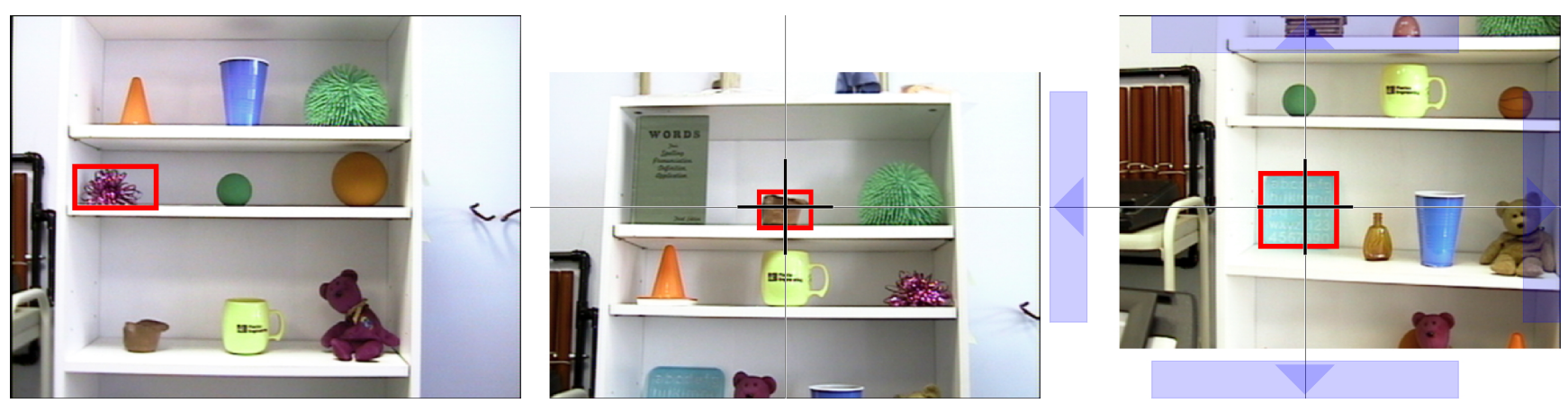

Figure 2: Object selection using our flexible interface. The fixed camera view selection is shown on the left. The moving camera view is shown center and right, using joystick and touch screen, respectively.

in Table 1. Based upon these traits, users with particular traits may be able to use one version of the interface better than another.

\section{EXPERIMENT METHODOLOGY}

An extended trial was run in August and September 2007 to evaluate the effectiveness of the visual interface used to control the Manus ARM. The participants in this experiment are representative of the intended end user.

\subsection{Participants}

The assistive technology director of Crotched Mountain played the central role in recruitment of participants. Given all of the students and the residents, the director evaluated their overall physical dexterity, cognitive ability, visual ability, and access method. Candidate participants were invited to participate in the experiment. Eight participants consented: three were their own guardians, and the remaining five required parental or guardian approval.

All participants had medium to high cognitively functional ability, minor vision impairment, and were able to operate a joystick or touch screen (finger isolation for pointing only). Eight people participated in the experiment: four men and four women. Participants' ages ranged from seventeen to sixty. Five of the participants are students of the Crotched Mountain School; three were diagnosed with Cerebral Palsy, one with Spinal Biffida, and one with Osteogenesis Imperfecta. The remaining three participants are patients of the Crotched Mountain Rehabilitation Brain Injury Center; all were diagnosed with Traumatic Brain Injury. Three participants use a power wheelchair, four use a manual wheelchair, and one is able to use both. All participants are capable of operating a joystick as an access method, although to varying degrees. Table 1 describes the participants' visual abilities, cognitive abilities, behavioral abilities, and computer access devices.

Each participant was given an initial interface settings profile by an assistive technologist. A profile contains parameters for access method (joystick or touch screen) based upon the participant's accessibility and behavioral abilities; fixed camera view or moving based on their level of cognition; cursor size based upon their visual acuity; cursor speed (if applicable) based on their physical dexterity; and dwell length (if applicable) also based in their physical dexterity. For example, one user who might hit the touch screen was assigned the joystick as her access method to prevent injury to the patient and equipment.

\subsection{Experiment Design and Conduct}

Four conditions were tested, joystick versus touch screen access method and fixed camera versus moving camera: ${ }^{3}$

Interface A (figure 2 left) had a fixed camera view displayed on the screen. The participant was to touch the screen on the desired object to indicate object selection.

Interface B (figure 2 left) also had a fixed camera view. The participant was to use a joystick to move to the desired object then press a button on the joystick indicating selection.

Interface $\mathbf{C}$ (figure 2 right) had a moving camera view displayed on the screen. The participant was to use buttons shown on the screen to move the camera up, down, left, and right to center the camera on the desired object, then press an external switch to indicate selection.

Interface D (figure 2 center) also had a moving camera. The participant was to use a joystick to move the camera up, down, left, and right to again center the camera on the desired object, then press and external switch to indicate selection.

The experiments were conducted by assistive technology technicians at Crotched Mountain. Consent was obtained for each participant through their Assistive Technology Unit. The initial profile, described in section 5.1, was used during the participant's first session. The profile was iteratively adjusted as needed each session by the experimenters.

We believe it is important to find tasks that have appropriate demands on the user. Tasks should be demanding enough to be interesting and stimulating without the negative result of being frustrating and discouraging, which is often referred to as the "just right challenge." For this experiment, matching was decided to be an appropriate task. The user would be asked to match the flash card of an object with the object displayed on the screen in front of them.

The objects were placed on a three-shelved bookshelf in one of four scenarios, according to difficulty, as seen in figure 3. The scenarios were generated by the experimenters prior to commencing user testing. Size, color, and reflectivity of the objects were taken into account when designing the scenarios. The task level could be adjusted by prompting the participant to select larger or smaller objects, or the configuration could change entirely.

\footnotetext{
${ }^{3}$ The baseline comparison using a menu hierarchy was deemed too challenging for the majority of our participants. As this is on-going, multi-year work, the occupational therapist wanted a positive experience with the rbot. Thus, the four conditions were tested against each other.
} 
Table 1: Participant profiles

\begin{tabular}{|c|c|c|c|c|c|c|c|}
\hline & Age & Diagnosis & Cognition & Behavior & Vision & Wheelchair & Computer \\
\hline$\overline{\mathrm{P} 1}$ & 26 & $\begin{array}{l}\text { Spinal Cord In- } \\
\text { jury, Traumatic } \\
\text { Brain Injury }\end{array}$ & $\begin{array}{l}\text { Not significantly im- } \\
\text { paired }\end{array}$ & "None & Typical & "Manual & Standard \\
\hline P2 & 60 & $\begin{array}{l}\text { Traumatic Brain } \\
\text { Injury }\end{array}$ & Distractible & $\begin{array}{l}\text { Very sociable; fol- } \\
\text { lows prompts well }\end{array}$ & $\begin{array}{lr}\text { Left inatten- } \\
\text { tion; right } \\
\text { visual process- } \\
\text { ing disorder }\end{array}$ & Manual & Standard \\
\hline P3 & 17 & Spinal Bifida & $\begin{array}{l}\text { Good memory and recep- } \\
\text { tive/expressive language }\end{array}$ & $\begin{array}{l}\text { Low frustration tol- } \\
\text { erance; needs en- } \\
\text { couragement }\end{array}$ & Reduced acuity & Manual & $\begin{array}{l}\text { Standard } \\
\text { (limited } \\
\text { dexterity) }\end{array}$ \\
\hline P4 & 20 & Cerebral Palsy & $\begin{array}{l}\text { Good receptive language } \\
\text { and expression with } \\
\text { AAC; able to learn new } \\
\text { skills; mild limitation } \\
\text { with problem solving }\end{array}$ & $\begin{array}{lr}\text { Aggressive } & \text { when } \\
\text { frustrated; } & \text { can } \\
\text { express need for } \\
\text { break }\end{array}$ & Functional & $\begin{array}{l}\text { Manual, } \\
\text { Power }\end{array}$ & $\begin{array}{l}\text { Dynavox } \\
\text { with key- } \\
\text { guard }\end{array}$ \\
\hline P5 & 20 & Cerebral Palsy & $\begin{array}{l}\text { Below age level; moder- } \\
\text { ate decision making abil- } \\
\text { ity }\end{array}$ & $\begin{array}{ll}\text { Needs } & \text { encourage- } \\
\text { ment } & \end{array}$ & Functional & Power & $\begin{array}{l}\text { Standard } \\
\text { (limited } \\
\text { dexterity) }\end{array}$ \\
\hline P6 & 37 & $\begin{array}{l}\text { Traumatic Brain } \\
\text { Injury }\end{array}$ & $\begin{array}{l}\text { Challenged by multi-step } \\
\text { process; short term mem- } \\
\text { ory impairment }\end{array}$ & None & Functional & Manual & Standard \\
\hline P7 & 20 & $\begin{array}{l}\text { Osteogenesis Im- } \\
\text { perfecta }\end{array}$ & $\begin{array}{l}\text { Mild deficits; slight } \\
\text { prompting needed due to } \\
\text { vision }\end{array}$ & Cooperative & $\begin{array}{ll}\text { Mild } & \text { percep- } \\
\text { tual } & \text { impair- } \\
\text { ment } & \end{array}$ & Power & Standard \\
\hline P8 & 18 & Cerebral Palsy & $\begin{array}{l}\text { Mild deficits; slightly } \\
\text { below age level; slight } \\
\text { prompting needed }\end{array}$ & None & Functional & Power & $\begin{array}{l}\text { Standard } \\
\text { (limited } \\
\text { dexterity) }\end{array}$ \\
\hline
\end{tabular}

At the start of a session, the experimenter temporarily attached the Manus ARM to the participant's wheelchair and positioned the touch screen towards the participant at a comfortable viewing height (see Figure 4). The experimenter summarized the participant's previous session. The experimenter then described the interface to be used in the current session, ${ }^{4}$ method for object selection, and Manus ARM movement. The participant was then trained on the interface. Training was necessary to minimize the learning effect and to refresh a participant's memory, if necessary. The goal was the same for all interfaces: to select a given object. The participant familiarized him/herself with the access method, means of selection, and process flow.

Once comfortable with the task, the experimenter prompted the participant with a flash card of the object. The experimenter then encouraged as necessary until the participant selected the object. If an object was able to be discerned, a red rectangle was displayed around all or part of the object accompanied with a "ding" audio cue. Otherwise, a "Please, try again!" prompt sounded. If the red rectangle was on or around the desired object and the participant indicated his/her intention, the experimenter signaled for the Manus ARM to unfold, extend towards the object, take a picture, and refold. Otherwise, the experimenter continued to prompt until a selection of the desired object occurred.

A run began when the experimenter prompted the participant with a flash card of the desired object and ended when the Manus ARM returned to its folded in position. Each flash card was used only once per session. A session consisted of three runs, maximizing the participant's attention and minimizing exhaustion and behavioral issues. At the conclusion of a session, the experimenter administered

\footnotetext{
${ }^{4}$ Typically, a single interface was used during each testing session due to the need to limit the session length to minimize exhaustion and prevent behavioral issues from arising.
}

a survey, moved the touch screen back, and removed the Manus ARM from the participant's wheelchair. The duration for each session averaged thirty minutes.

\subsection{Data Collection}

Data was collected from manual logs, post-session questionnaires, and computer generated log files. Each session was video recorded. Qualitative data included the postexperiment questionnaire administered at the end of each user session and the observer notes. The questionnaire posed open ended questions about which interface the user liked most, which interface they liked least, and suggestions for improving the interface. Observer notes contained relevant notes about the session, including length of reorientation.

Quantitive data included trial run time, attentiveness rating, prompting level, close up photos of the object selected, and computer generated log files. For each trial, the run time was recorded, specifically the time from object prompt to participant selection, the time from the Manus ARM movement to the object visually confirmed, and the time for the Manus ARM to complete folding. The experimenter, who is an assistive technologist professional, rated the user's prompting level per trial based on the FIM scale, where 0 indicated "no prompting needed" and 5 indicated "heavy prompting needed" [10]. The experimenter also rated the user's attentiveness to the task on a Likert scale, where 0 indicated "no attention" and 10 indicated "complete attention." Two separate scales were used because it is not necessarily the case that a person who requires high levels of prompting is unmotivated to complete the task.

\section{RESULTS AND DISCUSSION}

Hypothesis 1 (Ease of use): Although difficult to quantify, object selection time can be viewed one a measure of ease of use of the interface. The overall participants' mean 
Table 2: Participant time to object selection (in seconds). Sessions are grouped into tuples; for example, Sx: $(m, n)$ translates to "session $x$, where run one took $m$ seconds and run two $n$ seconds."

\begin{tabular}{|c|c|c|c|c|}
\hline & $\begin{array}{l}\text { Interface } \mathbf{A} \\
\text { Fixed camera, touch screen }\end{array}$ & $\begin{array}{l}\text { Interface B } \\
\text { Fixed camera, joystick }\end{array}$ & $\begin{array}{l}\text { Interface } \mathbf{C} \\
\text { Moving camera, touch screen }\end{array}$ & $\begin{array}{l}\text { Interface D } \\
\text { Moving camera, joystick }\end{array}$ \\
\hline$\overline{\mathbf{P 1}}$ & & & & $\begin{array}{l}\text { S1: }(94.72,46.8,4.43) \\
\text { S2: }(1.67,2.58,2.26,17.03)\end{array}$ \\
\hline $\mathbf{P 2}$ & $\begin{array}{l}\text { S1: }(6.22,69.33,4.18) \\
\text { S2: }(0,0,0)\end{array}$ & S6: $(5,4,6)$ & $\begin{array}{l}\text { S3: }(12.93,38.2,0) \\
\text { S4: }(1.94,6,6) \\
\text { S7: }(1,4,2) \\
\text { S8: }(2,4,4,3)\end{array}$ & $\begin{array}{l}\text { S5: }(2,88,92,3) \\
\text { S6: }(4)\end{array}$ \\
\hline$\overline{\text { P3 }}$ & S3: $(3.28,2,7)$ & S4: $(2,4,1)$ & S2: $(57.7,5,4.11)$ & $\begin{array}{l}\text { S1: }(3,2,2) \\
\text { S5: }(0,5,2)\end{array}$ \\
\hline $\mathbf{P 4}$ & $\begin{array}{l}\text { S1: }(175,0,5) \\
\text { S4: }(2,1)\end{array}$ & $\begin{array}{l}\text { S2: }(10,9,7) \\
\text { S3: }(2,5,5) \\
\text { S6: }(1.01,0.4,0.49,1.1,0.06)\end{array}$ & $\begin{array}{l}\text { S4: }(2,3) \\
\text { S5: }(0.98,0.43,1.04)\end{array}$ & \\
\hline P5 & $\begin{array}{l}\text { S2: }(3.88,4,4.2) \\
\text { S3: }(0,0,3,2,4,3)\end{array}$ & S1: $(12,53,5.39)$ & & \\
\hline P6 & & S1: $(7,5,8)$ & S2: $(4,6,1)$ & \\
\hline P7 & & S1: $(2,2)$ & & S1: $(35.8)$ \\
\hline P8 & S1: $(2,2,2,0)$ & & S1: (3) & S2: $(1,4,2,2)$ \\
\hline
\end{tabular}

Table 3: Participant attentiveness (0 low to 10 high)

\begin{tabular}{|c|c|c|c|c|}
\hline & $\begin{array}{l}\text { Interface } \mathbf{A} \\
\text { Fixed camera, touch screen }\end{array}$ & $\begin{array}{l}\text { Interface B } \\
\text { Fixed camera, joystick }\end{array}$ & $\begin{array}{l}\text { Interface } \mathbf{C} \\
\text { Moving camera, touch screen }\end{array}$ & $\begin{array}{l}\text { Interface D } \\
\text { Moving camera, joystick }\end{array}$ \\
\hline$\overline{P 1}$ & & & & $\begin{array}{l}\text { S1: }(8,10,10) \\
\text { S2: }(10,-,-, 10)\end{array}$ \\
\hline P2 & $\begin{array}{l}\text { S1: }(-, 0,4) \\
\text { S2: }(6,5,3)\end{array}$ & S6: $(10,-, 10)$ & $\begin{array}{l}\text { S3: }(10,7,6) \\
\text { S4: }(10,5,10) \\
\text { S5: }(4,2,10) \\
\text { S6: }(10,10,6.5,10)\end{array}$ & $\begin{array}{l}\text { S5: }(4,10,6,3) \\
\text { S6: }(10)\end{array}$ \\
\hline P3 & S3: $(10,10,10)$ & S4: $(10,10,10)$ & S2: $(10,9,9)$ & $\begin{array}{l}\text { S1: }(10,10,10) \\
\text { S5: }(10,10,10)\end{array}$ \\
\hline $\mathbf{P 4}$ & $\begin{array}{l}\text { S1: }(5,5,3) \\
\text { S4: }(3,3)\end{array}$ & $\begin{array}{l}\text { S2: }(3,2.5,8) \\
\text { S3: }(3,4,2) \\
\text { S6: }(2,3,2)\end{array}$ & $\begin{array}{l}\text { S4: }(2,3) \\
\text { S5: }(4,10,-)\end{array}$ & \\
\hline P5 & $\begin{array}{l}\text { S2: }(10,10,10) \\
\text { S3: }(10,6,10,9,-, 10)\end{array}$ & S1: $(9,10,10)$ & & \\
\hline P6 & & S1: $(10,10,10)$ & S2: $(10,10,10)$ & \\
\hline P7 & & S1: $(10,10)$ & & S1: (10) \\
\hline P8 & S1: $(10,10,10,10)$ & & S1: $(10)$ & S2: $(10,10,10,10)$ \\
\hline
\end{tabular}

Table 4: Participant prompting level (0 low to 5 high)

\begin{tabular}{|c|c|c|c|c|}
\hline & $\begin{array}{l}\text { Interface } \mathbf{A} \\
\text { Fixed camera, touch screen }\end{array}$ & $\begin{array}{l}\text { Interface B } \\
\text { Fixed camera, joystick }\end{array}$ & $\begin{array}{l}\text { Interface } \mathbf{C} \\
\text { Moving camera, touch screen }\end{array}$ & $\begin{array}{l}\text { Interface D } \\
\text { Moving camera, joystick }\end{array}$ \\
\hline$\overline{\mathbf{P 1}}$ & & & & $\begin{array}{l}\text { S1: }(0,0,0) \\
\text { S2: }(0,-,-, 0)\end{array}$ \\
\hline $\mathbf{P 2}$ & $\begin{array}{l}\text { S1: }(0,1,3) \\
\text { S2: }(0,0,0)\end{array}$ & S6: $(0,-, 0)$ & $\begin{array}{l}\text { S3: }(0,2,4) \\
\text { S4: }(0,2,0) \\
\text { S7: }(0,2,2) \\
\text { S8: }(4,5,3.5,0)\end{array}$ & $\begin{array}{l}\text { S1: }(0,3,0,1) \\
\text { S5: }(2)\end{array}$ \\
\hline P3 & S3: $(2,0,0)$ & S4: $(0,0,0)$ & $\mathrm{S} 2:(1,1,0)$ & $\begin{array}{l}\text { S1: }(1,0,3) \\
\text { S5: }(0,0,0)\end{array}$ \\
\hline$\overline{\mathbf{P 4}}$ & $\begin{array}{l}\text { S1: }(5,0,0) \\
\text { S4: }(1,0)\end{array}$ & $\begin{array}{l}\text { S2: }(3,3,0) \\
\text { S3: }(3,3,3) \\
\text { S6: }(-,-,-)\end{array}$ & $\begin{array}{l}\text { S4: }(2,3) \\
\text { S5: }(3,5,5)\end{array}$ & \\
\hline P5 & $\begin{array}{l}\text { S2: }(3,0,0) \\
\text { S3: }(0,0,0,0,-, 0)\end{array}$ & S1: $(1,2,0)$ & & \\
\hline P6 & & S1: $(2,3,0)$ & S2: $(2,2,2)$ & \\
\hline P7 & & S1: $(1,0)$ & & S1: (0) \\
\hline P8 & S1: $(0,0,0,0)$ & & S1: (1) & $\mathrm{S} 2:(3,4,0,0)$ \\
\hline
\end{tabular}


time from prompt to object selection ranged from 5.87 seconds to 18.14 seconds; however, the median selection time was much more similar (2 (SD 35.21), 4 (SD 9.75), 3.5 (SD 13.71), and 3 (SD 31.27) seconds respectively). Paired ttests assuming unequal variance were used for statistical analysis. Participants were found to perform better in Interface $\mathrm{C}$ (moving camera view with touch screen) than Interface $\mathrm{D}$ (moving camera view with joystick), with $\mathrm{p}<0.01$ given alpha $=0.05$. Also, participants were found to perform better in Interface B (fixed camera view with joystick) and Interface D (moving camera view with joystick), with $\mathrm{p}<0.01$ given alpha $=0.05$.

Other measures of ease of interface use were the participants' attentiveness and prompting levels. Participants were found to have more attention in Interface A (fixed camera view with touch screen) than Interface $C(p<0.01$, alpha $=0.05)$, and Interface B than D $(\mathrm{p}<0.01$, alpha $=0.05)$. Since we did not have any participants with short-term memory impairments, prompting levels may be inversely correlated to ease of use and motivation. Participants were also found to require less prompting in these cases (both $\mathrm{p}<0.01$, alpha $=0.05)$, and for Interface A than Interface B.

In twenty of the post-experiment surveys ${ }^{5}$, the participants specifically expressed their preference for particular interfaces in the first two open-ended questions ("Which interface did you like the best? Why?" and "Which interface did you like the least? Why?"). Interface B was the most liked with seven positive comments $(\mathrm{p}<0.02$, alpha $=0.05)$. Interfaces $\mathrm{A}$ and $\mathrm{C}$ received mixed reviews with four positive/two negative and four positive/one negative respectively. Interface D received was the least liked interface with four negative remarks.

There were also general comments about the access devices and camera movement. P2 indicated her preference for both the touch screen and joystick on two separate occassions. P3 twice stated her preference for the touch screen and once stated her dislike of the joystick. P8 commented that "[the] moving camera felt more real" and that "[the] fixed camera [was] too easy." On two separate occasions, she gave negative comments towards Interface A.

Hypothesis 2 (Fixed camera view preference to moving camera): In statistical analysis over selection time, attention, and prompting, the fixed camera view interfaces outperformed the moving camera view interfaces, except in the case of Interface B and D with respect to time. The users also selected interface D, a moving camera view, as

${ }^{5}$ The remaining of twenty nine surveys had no response.



Figure 3: The level of challenge varies with the number of objects in the scene and the size of the object.

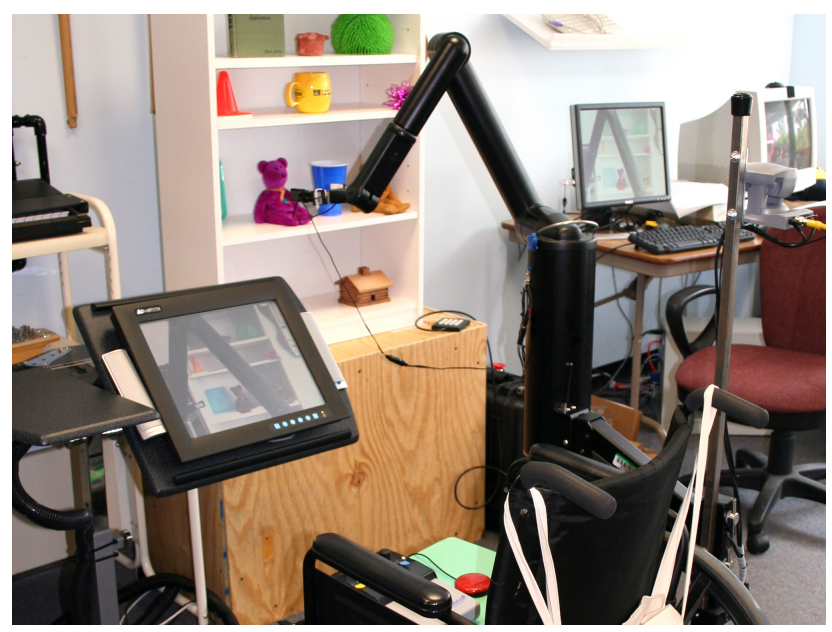

Figure 4: Experiment setup

their least favorite, and Interface A, a fixed camera view, as their most preferred.

Hypothesis 3 (Correlation with abilities): Due to the small sample size and sparsity of data of certain conditions in this experiment, we do not wish to make generic claims. In future experiments, the participant population will contain a larger variation in cognitive ability. However, interestingly, two diagnoses dominated the participant pool: traumatic brain injury (TBI) and cerebral palsy (CP). Statistical analysis was conducted using paired t-tests with unequal variances on selection time. The participants were divided into TBI versus non-TBI and $\mathrm{CP}$ versus non-CP. The selection times of the TBI patients versus non-TBI patients were not statistically significant. However, the selection times of $\mathrm{CP}$ patients were faster than non-CP patients for both moving camera conditions $(\mathrm{p}<0.01$, alpha=0.05).

Additionally, intuitions can be drawn from observations of the experiments. For example, one participant (P5) uses an alternative augmentative communication (AAC) device with a keyguard on a daily basis. His finger isolation is quite good even when in an emotionally excited state. In one session, Interface $\mathrm{C}$ was selected. He understood the process for selection quickly and trained easily in one run. However, when the recorded run began, his finger isolations were not directly on the blue buttons. Each missed button pressed equated to an inadvertent object selection. The selections queue rapidly and the vision processing algorithm was not able to discern an object. The delayed response of "Please, try again!" caused frustration. He continued to try to move the camera, and the selections continued to queue. He pushed the touch screen away indicating his frustration. In the participant's previous session, three successful runs were executed with Interface B; in the participant's following run another three successful runs and one system failure were executed with Interface A. In a post-experiment survey, he indicated that he like Interface A the best. This selection is consistent with his current access methods.

Another participant (P1) had been asked to evaluate the original keypad menuing interface in addition to the flexible interface. He successfully learned and executed three runs in the span of an hour. He commented that the keypad was "easier to use" while the joystick control in Interface C had "too much play" (drift). This participant has high cognitive 
ability and his preference for the original keypad echoes the findings of the August 2006 experiments with able-bodied participants [18]. The following week, he was able to try the remaining versions of the flexible interface. When he used Interface A, he remarked that he liked it the best because it was the most intuitive. He later noted that he still liked the original keypad interface.

User Requests: The third question of the post-experiment questionnaire asked "What would make the system easier to use?" With respect to system improvements, there were two recurring comments - joystick sensitivity and system responsiveness. The first related to the drift of the cross hairs over the object in the moving camera interfaces, especially the joystick version of the interface. There were three specific statements about this in the post-experiment surveys. One user remarked that "the joystick [would make the system easier to use] if there wasn't any drift."

Two participants wished for the system to be more responsive. The system would seem to "pause" when object selection occurred. On sunny days, object selection was fast because the histogram analysis provided a training color with tight thresholds. Object selection seemed to take slightly longer on cloudy days or in the late afternoon.

Other features desired of the robot arm included voice activation, additional auditory feedback, and grasping the object instead of taking a picture.

\section{CONCLUSIONS AND FUTURE WORK}

The current system has several assumptions which will need to be addressed. The shoulder camera view is assumed to approximate that of the wheelchair occupant, which may not be true as some users may have permanent vision loss and others may have temporary blurring. Also, the touch screen serves as the display for the interface, which represents a layer of abstraction between the user and the objects in the real world. Some users may be able to understand a real apple but not a picture of it. Despite these limitations, the work described in this paper has outlined methods for designing human-robot interaction for assistive technology and assessments of these systems with the intended users.

\section{ACKNOWLEDGMENTS}

This work is supported by the National Science Foundation (IIS-0534364). Special thanks to all the Crotched Mountain participants, Tae-Young Park of Crotched Mountain, and Philip Thoren, Mark Micire, Munjal Desai, Harold Bufford, and Jeremy Badessa, all of UMass Lowell.

\section{REFERENCES}

[1] A. Agarwal. MS Thesis: User Modeling for Individuals with Disabilities. Univ. of Pittsburgh, 2005.

[2] P. Athanasiou, N. Chawla, and E. Leichtnam. Assistive robotic manipulator interface. In IEEE 32nd Annual Northeast Bioengineering Conference, pages 171-172, Easton, PA, 2006.

[3] S. Card, T. Moran, and A. Newell. The Psychology of Human-computer Interaction. Erlbaum, 1983.

[4] B. Driessen, F. Liefhebber, T. Kate, and K. Van Woerden. Collaborative control of the manus manipulator. In IEEE Int. Conf. on Rehabilitation Robotics (ICORR), pages 247-251, June 2005.
[5] C. Dune, C. Leroux, and E. Marchand. Intuitive human interactive with an arm robot for severely handicapped people - a one click approach. In IEEE Int. Conf. on Rehabilitation Robotics, ICORR'2007, pages 582-589, The Netherlands, June 2007.

[6] Exact Dynamics. Assistive robotic manipulator. In http://www.exactdynamics.nl/, September 2007.

[7] M. Ghorbel, R. Kadouche, and M. Mokhtari. User \& service modeling in assistive environment to enhance accessibility of dependent people. In ICTA, April 2007.

[8] T. King. Assistive Technology: Essential Human Factors. Allyn \& Bacon, 1999.

[9] C. Leroux, M. Guerrand, C. Leroy, Y. Measson, and B. Boukarri. Magritte: a graphic supervisor for remote handling interventions. In ESA Workshop on Advanced Space Technologies for Robotics and Automation, ASTRA 2004, The Netherlands, Nov. 2004.

[10] MedFriendly. Medfriendly.com: Functional independence measure. In http://www.medfriendly.com/ functionalindependencemeasure.html, September 2007.

[11] R. Oppermann. Adaptive User Support: Ergonomic Design of Manually and Automatically Adaptable Software. Lawrence Erlbaum Associates, 1994.

[12] B. Robins, K. Dautenhahn, R. te Boekhorst, and A. Billard. Robots as assistive technology - does appearance matter? In IEEE International Workshop on Robot and Human Interactive Communication, September 2004.

[13] B. Scassellati. Quantitative metrics of social response for autism diagnosis. Robot and Human Interactive Communication, 2005. ROMAN 2005. IEEE International Workshop on, pages 585-590, 2005.

[14] B. Schneiderman. Universal Usability. Communications of the ACM, 43(5):85-91, 2000.

[15] B. Shneiderman. Designing the user interface: strategies for effective human-computer interaction. Addison-Wesley Longman Publishing Co., Inc. Boston, MA, USA, 1992.

[16] C. Tan, W. Yu, and G. McAllister. ENABLED Adaptive Architecture to Improve Internet Accessibility. Proc. 2nd Int'l. Conf. on Enactive Interfaces, 2005.

[17] H. Tijsma, F. Liefhebber, and J. Herder. Evaluation of new user interface features for the manus robot arm. In IEEE Int. Conf. on Rehabilitation Robotics, ICORR'2005, pages 258-263, June 2005.

[18] K. Tsui and H. Yanco. Simplifying wheelchair mounted robotic arm control with a visual interface. In AAAI Spring Symposium on Multidisciplinary Collaboration for Socially Assistive Robotics, pages 247-251, Palo Alto, CA, March 2007.

[19] University of Texas Austin. Accessibility and disability defined. In http://www.utexas.edu/learn/accessibility/ disability.html, December 2007.

[20] G. Vanderheiden. Universal design and assistive technology in communication and information technologies: alternatives or complements? Assist Technol, 10(1):29-36, 1998.

[21] R. Woodworth. The accuracy of voluntary movement. In Psychology Review Monograph Supplement, 1899. 